\title{
Experimental and numerical investigations on fracture behavior of high silica glass/satin textile fiber reinforced hybrid polymer composites
}

\author{
P.S. Shivakumar Gouda ${ }^{\star}$, Krishnaraja G. Kodancha ${ }^{2}$, Siddaramaiah $^{3}$, Dayananda Jawali ${ }^{4}$ \\ ${ }^{1}$ Advanced Composite Center for Innovation and Science (ACCIS), University of Bristol, Bristol, BS8 1TR, UK and Dept. of \\ Mech. Engineering, SDM College of Engineering \& Tech, Dharwad 580 002, India \\ ${ }^{2}$ Dept. of Automobile Engineering, BVB College of Engineering \& Tech, Hubli 580 031, India \\ ${ }^{3}$ Dept. of Polymer Technology, S.J. College of Engineering, Mysore 570 006, India \\ ${ }^{4}$ Dept. of Mechanical Engineering, S.J. College of Engineering, Mysore 570 006, India
}

*Corresponding author. Tel.: (+44) 7451836390; E-mail: ursshivu@ gmail.com

Received: 28 March 2013, Revised: 08 May 2013 and Accepted: 12 May 2013

\section{ABSTRACT}

The fracture behavior of a high silica glass-satin textile fiber reinforced hybrid polymer composite (HPC) under the full range of in-plane loading conditions has been investigated experimentally and numerically. Loading conditions from pure mode- I, through various mixed mode I/II ratios up to pure mode II have been generated by the aid of the proposed compound version of the CTS (compact tension shear) specimen. From the experimentally measured critical loads, the mode I, mode II and the various mixed mode I/II critical stress intensity factors at crack initiation have been determined by the aid of finite element analysis. Based on these results the parameters for a fracture criterion for the composite under consideration have been determined. After testing, both edges of the sample and the fracture surfaces were examined with a scanning electron microscope (SEM). The results infer that the ascendancies of Mode-I and Mode -II are highly dependent on loading angle (LA). Copyright (C) 2013 VBRI press.

Keywords: Mix mode fracture toughness; compact tension shear specimen; hybrid polymer composite; stress intensity factor.

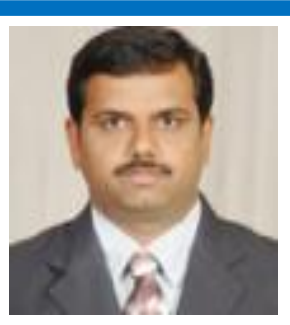

P.S. Shivakumar Gouda is currently working as a Visiting Researcher for the period of one year at Advanced Composites Centre for Innovation and Science (ACCIS), University of Bristol, United Kingdom, sponsored under Commonwealth Scholarship and Fellowship Commission, United Kingdom, for the year 2012-2013, presently he is a Assistant Professor in the Department of Mechanical Engineering, SDM College of Engineering and Technology, Dharwad, Karnataka India. He hold his M.Tech in Machine Design and B.E degree from Visvesvaraya Technological University, Belgaum, India, in 2005 and 2003 respectively. He was awarded Young Scientist from Swdeshi Vijana Andolana, Bangalore in Association with Karnatak University Dharwad, India, 2006. Presently he is doing research studies on Fracture and finite element analysis of hybrid polymer composites under Visvesvaraya Technological University, Belgaum, India. He has published about six papers in national and international journals and 14 papers in conference proceedings.

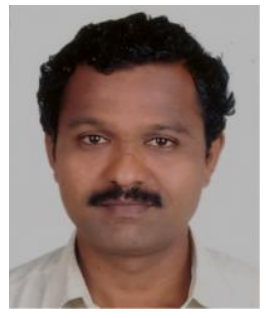

Krishnaraja G. Kodancha, born on $20^{\text {th }}$ July 1970 at Udupi in Karnataka state. He received his Bachelor of Engineering degree (Automobile) from Karnataka University, Dharwad in 1992 and Masters Degree in Mechanical Engineering (Design Engineering) from Indian Institute Technology Madras, Chennai in 2002. He received his doctoral degree in the area of constraint issues in fracture from Visvesvaraya Technological University, Belgaum, Karnataka, India in 2012. The academic interest led him to accept teaching profession, and joined as a Lecturer in B. V. Bhoomaraddi College of Engineering and Technology, Hubli in 1992. Presently he is working as a Professor, Automobile Engineering and coordinator, PG (Machine Design) in the same college. The author has Twenty one years of teaching experience, and several publications to his credit.

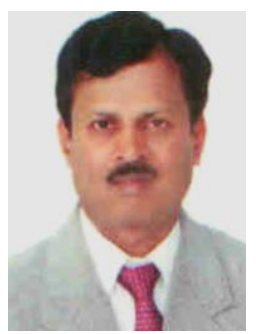

Siddaramaiah, obtained his Ph.D., degree (1993) from University of Mysore, Mysore, India. After this, he joined the Department of Polymer Science \& Technology, Sri Jayachamarajendra College of Engineering, Mysore, India. He visited Institute of Macromolecules, Rio de Janeiro, on TWASUNESCO fellowship (2005 \& 2008) and Department of Polymer \& Nano Science and Technology, Chonbuk National University, Jeonju, South Korea, on Brain Korea (BK-21) fellowship (2007-08) for postdoctoral research work. His primary research interest in the field of polymer biocomposites, PU based IPNs, conducting polymers and polymer membranes. He has to his credit many awards and has guided seventeen Ph.D., thesis. He has more than 250 research papers, one book, one review article, three book chapters and 2 Indian patents to his credit. 


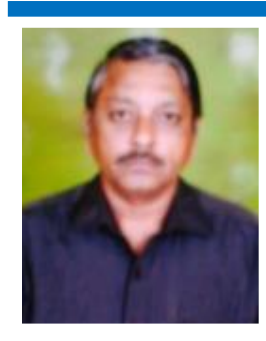

Dayananda Jawali, obtained his Ph.D., degree (2008) from University of Kuvempu, Shimoga,India and Master of technology in Machine design from IIT Delhi India. He is currently working as a Professor in the Department of mechanical engineering, Sri Jayachamarajendra College of Engineering, Mysore, India. His research interest in the field of polymer composites for wear and Fracture studies. $\mathrm{He}$ has to his credit many awards and has currently supervising $5 \mathrm{Ph} . \mathrm{D}$ students in which one is currently doing research studies in Advanced Composite Center for Innovation and Sciences (ACCIS), University of Bristol UK under Commonwealth Scholarships UK. He has more than 15 research papers and 20 conference papers to his credit.

\section{Introduction}

In recent years, composite materials have found increasing applications in construction, aerospace and automotive industries due to their good characteristics of light weight, improved strength, corrosion resistance, controlled anisotropic properties, reduced manufacturing and maintenance costs. However, there is a growing demand to improve upon composite materials with reduction in the cost of construction [1]. Hybrid Polymer Composites (HPC) are one of the recent developments to reduce the cost of expensive composites containing reinforcements like carbon fiber by incorporating a proportion of cheaper, low-quality fibers such as glass, textile, natural fibers etc., without reducing the mechanical properties of the original composite.

The properties of a hybrid composite mainly depend upon the fiber content, length of individual fiber, orientation, extent of intermingling of fibers, fiber to matrix bonding and arrangement of both the fibers. The strength of the hybrid composite is also dependent on the failure strain of individual fibers. Maximum hybrid results were obtained when the fibers were highly strain compatible [2].

Various attempts have been made to characterize fracture toughness under mode-I and mixed mode loading conditions, among beam type specimens is used commonly. If the so-called end loaded split (ELS) specimen was loaded by the upper arm, mixed-mode loading conditions at the crack tip are achieved. The mixed mode bending (MMB) test specimens have been proposed by combining the schemes used for double cantilever beam (DCB) $[3,4]$ and end notched flexure (ENF) tests to study mixed mode fracture toughness. However, for these test methods there are problems to create a wide range of mixed-mode ratios which limit their usefulness. Different beam type specimens would also be required in order to obtain reliable results for fracture toughness in pure mode-I, pure mode-II and mixed-mode loading conditions. It is therefore necessary to develop other test methods to evaluate the mixed mode fracture toughness under in-plane loading conditions starting from pure mode-I to pure mode-II.

Only limited work could be found in the literature regarding the mode-I, mode-II and mixed mode fracture behavior of hybrid composite materials [5-10] using compact tension shear (CTS) specimens. In the present investigation mode-I, mode-II and mixed mode fracture experiments were conducted on compact tension shear (CTS) specimen. The details of the specimen and fixtures are shown in Fig. 1.

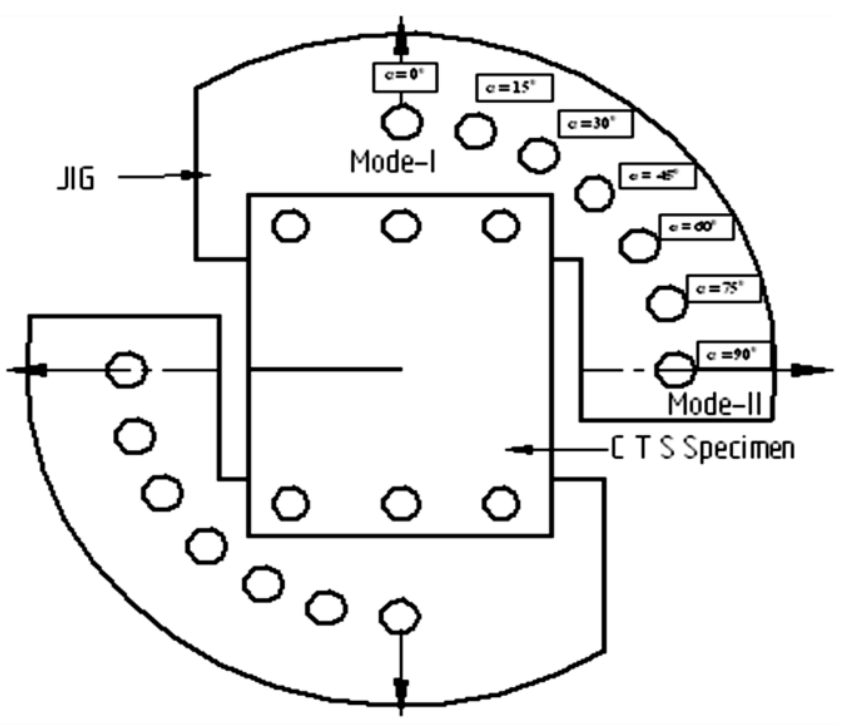

Fig. 1. CTS Specimen and loading fixture.

The fixture was modified for mode-I and mixed mode fracture tests. Then, numerical simulations of the fracture tests may be considered as being useful, at least, for two reasons. The first one is that the numerical simulations or virtual testing may replace many expensive and time consuming experiments. In this case, it is the necessary to test the numerical model in situation in which experimental results are easily available. The second one is that it is connected with the necessity to build new analytical models, and they can be compared with experimental results for the purpose of fitting the correct parameters of these models. Hence the title study was undertaken.

The most recent development is the proposed compound version of the CTS specimen which covers all in-plane mixed mode loading conditions, starting from pure mode- I through any mixed mode I/II ratio up to pure mode II loading. The CTS specimen proposed for fracture tests of isotropic materials under such general in-plane loading conditions, was found elsewhere [11-13]. The main novelty addressed in this work is how to overcome the offset loading when the CTS specimen is scaling up to the thickness of maximum $10 \mathrm{~mm}$, and accordingly the loading fixtures are designed to overcome the offset loading during mode-I, mode-II and mixed mode (I/II) in-plane fracture tests. The main objective of this study is to show the hybrid benefits in terms of fracture toughness properties by adding cheaper quality of woven satin textile fiber with woven high silica glass fiber reinforcement in order to reduce the cost of the hybrid composite system for the structural applications like aerospace, military and space settles etc, without seriously reducing its mechanical and morphological properties. Textile based hybrid polymer composites may have wide potential applications due to their excellent properties and the availability in a large quantity at low cost. 


\section{Experimental}

\section{Materials}

Hybrid composite materials reinforced with Glass-Satin textile Fiber are a new type of laminated composites, which are becoming increasingly popular for various structural applications in the automotive, aerospace and other industrial sectors. The present investigation has been carried out with epoxy resin (L12-3202) at a room temperature with a curing hardener (H6). All these polymer products were supplied by Atul Limited, Polymer Division (Gujarat, India). The plain Woven high silica glass having thickness $0.26 \mathrm{~mm}$ was manufactured by Interglass Technologies (Benzstrasse, Germany). The plain woven satin textile fiber having thickness $0.15 \mathrm{~mm}$ and 100\%polyester supplied by Wujiang Chunzhu Textile Auxiliaries Co., Ltd, chain.

\section{Fabrication of composite}

The aim of the test is to determine the fracture toughness of S-Glass-Satin-Epoxy thermosetting composite material. To prepare the specimens by hand layup method $[\mathbf{1 4}, \mathbf{1 5}], 18$ layers of cross-ply glass and satin laminates, each of 0.2 and $0.15 \mathrm{~mm}$ thickness alternatively of $350 \mathrm{~mm}$ length and $350 \mathrm{~mm}$ width were put together to form a block with dimension of $350 * 350 * 8 \mathrm{~mm}$ for fracture test. Similarly for tensile test, 6 layers alternatively of $350 \mathrm{~mm}$ length and $350 \mathrm{~mm}$ width and with the dimension of $350 * 350 * 4 \mathrm{~mm}$, were used.

\section{Tensile test}

The main aim of the tensile test is to determine the elastic properties of the selected material. This test was carried out as per the ASTM D3039 standard [16]. Glass-Satin textile fiber reinforced composite was taken in the form of $4 \mathrm{~mm}$ thick sheets. To test its orthotropic material properties, the specimens were machined from prepared block in two different directions along and across the fiber direction as shown in Fig. 2.
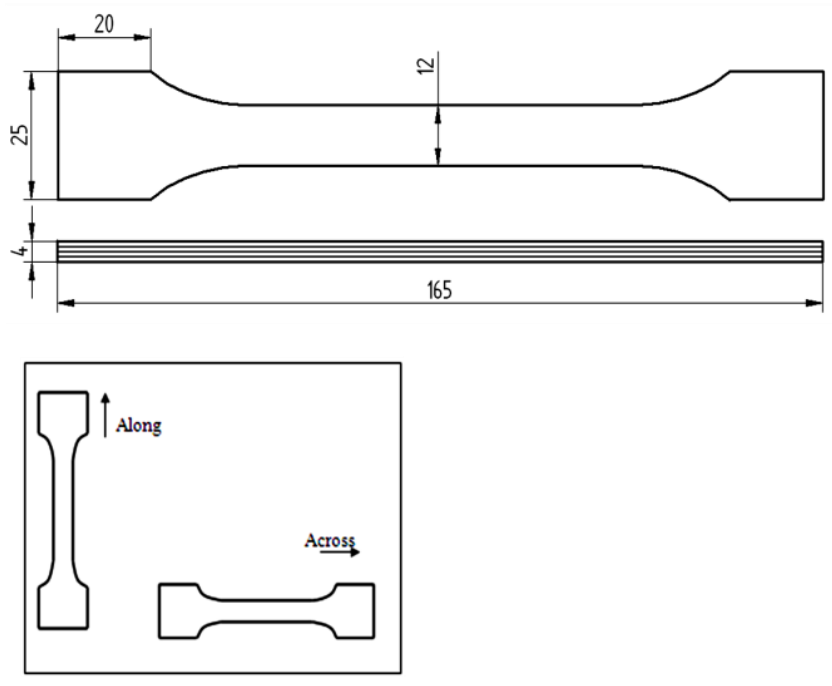

Fig. 2. Tensile specimen dimensions in $\mathrm{mm}$.

\section{Fracture test}

Mode-I and mixed mode (I/II) Fracture toughness test for S-Glass-satin textile reinforced epoxy composite was carried out as per s ASTM standards [17]. Mixed-mode (I/II) fracture tests were conducted on CTS specimens with a thickness of $8 \mathrm{~mm}$. The specimens were obtained in the in-plane loading. The initial notch depth was $45 \mathrm{~mm}$ and width of $0.25 \mathrm{~mm}$. Fig. 3 illustrates the major dimensions of the samples used in the tests and Fig. $\mathbf{4}$ shows mixed mode testing fixture for accommodating all the mixed mode angles for the CTS specimen from pure Mode I $\left(\alpha=0^{0}\right)$ to pure Mode -II $\left(\alpha=90^{\circ}\right)$.

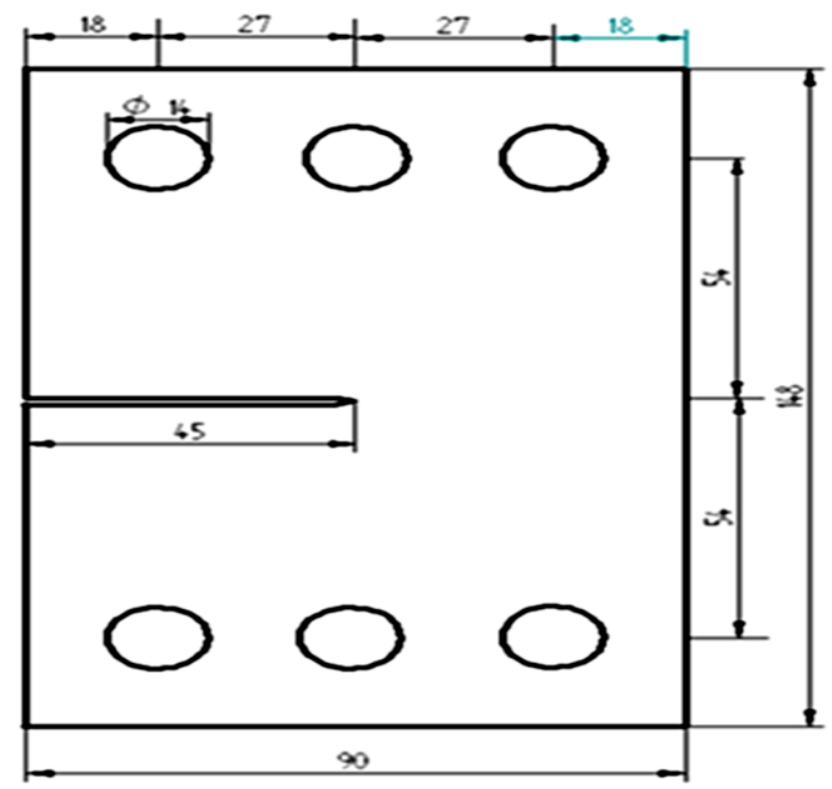

Fig. 3. Geometry of the CTS specimen (dimensions in $\mathrm{nm}$ ).

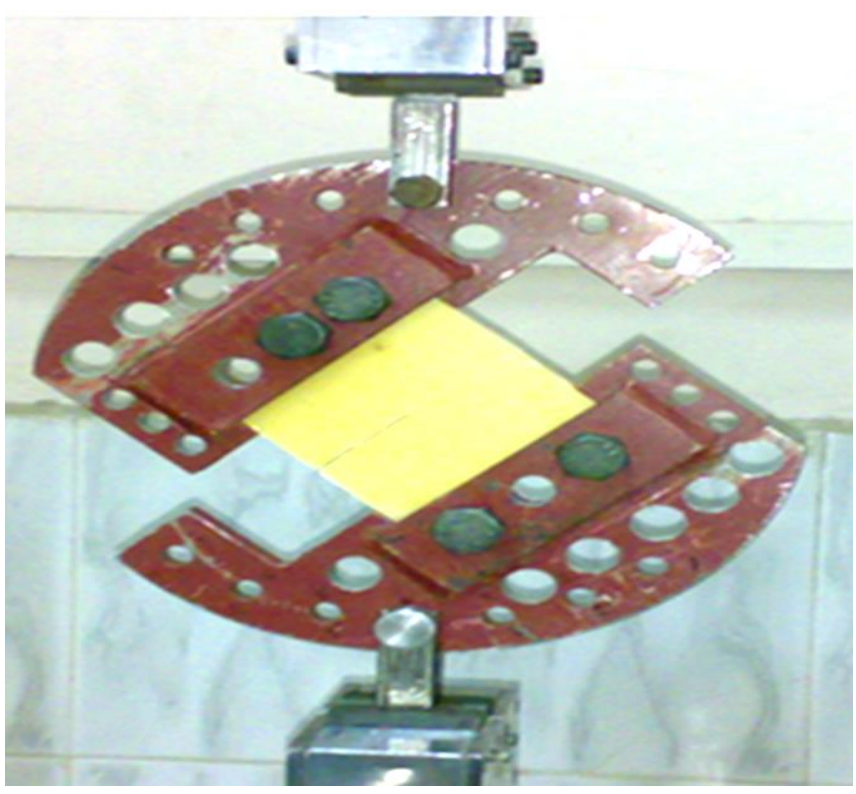

Fig. 4. Mixed mode testing fixture for CTS specimen (dimensions in $\mathrm{nm}$ ).

In this test method, a notched specimen was loaded in tension that has been pre-cracked. The load corresponding to a $2.5 \%$ apparent increment of crack extension was 
established by a specified deviation from the linear portion of the record. The critical stress intensity factor $\left(\mathrm{K}_{\mathrm{Ic}}\right)$ value was calculated from this load by equations that have been established on the basis of elastic stress analysis on specimens of the type described in the ASTM D 6671 standard [17]. The validity of the determination of the $\mathrm{K}_{\mathrm{Ic}}$ value by these test methods depends upon the establishment of a sharp-crack condition at the tip of the crack, in a specimen of adequate size to give linear elastic behavior.

\section{Test setup}

Specimens prepared in accordance with ASTM standards were loaded on a computer controlled Universal Testing Machine. The specimens were clamped in custom-built Transfixing fixture which were designed and fabricated using EN150 steel to perform the fracture test for mode-I and Mode-II. This was subjected to monotonic uniaxial tension at a displacement rate of $5 \mathrm{~mm} / \mathrm{min}$. The tests were closely monitored and conducted at room temperature, since it is difficult to detect the first point of damage in laminated composites. In order to overcome such difficulties, the applied loads are recorded. Using recorded values, the fracture toughness $\mathrm{K}_{\mathrm{IC}}$ and $\mathrm{K}_{\mathrm{IIC}}$ have been estimated by using load extension curve.

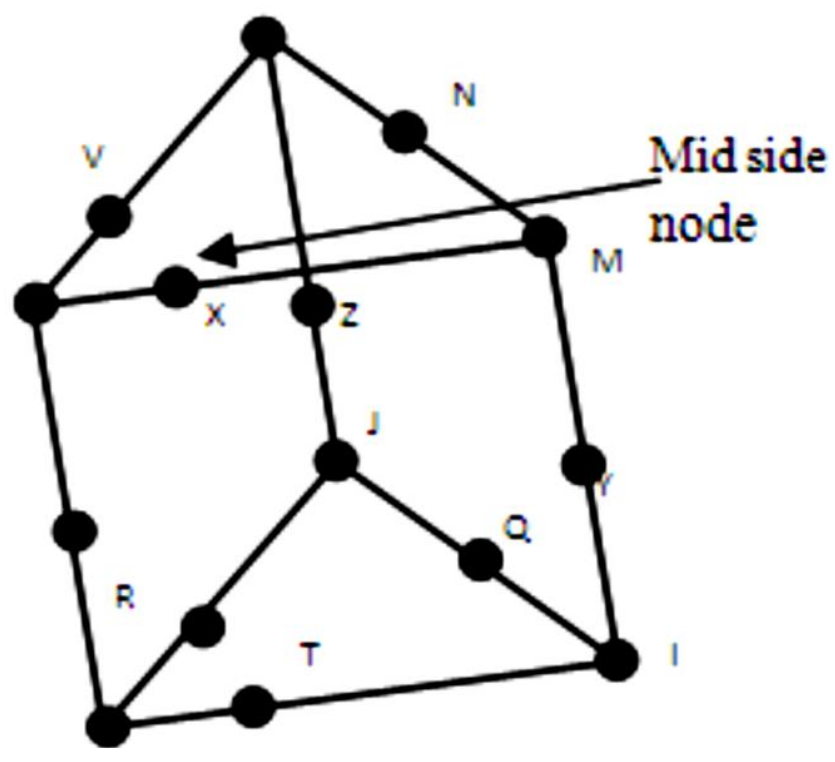

Fig. 5. Singular element of ANSYS.

\section{Finite element analysis of the fracture model}

A 3D Finite Element model is created to simulate fracture test in ANSYS [18]. Solving a fracture mechanics problem, involves performing a linear elastic or elastic-plastic static analysis and then use specialized post processing commands or macros to calculate desired fracture parameters [18]. In this section, two main aspects are focused: Modeling the Crack Region and estimating Fracture Parameters ( $\mathrm{K}_{\mathrm{IC}}$ and $\mathrm{K}_{\mathrm{IIC}}$ ) under plane strain conditions. The most important region in a Fracture model is the region around the edge of the crack.

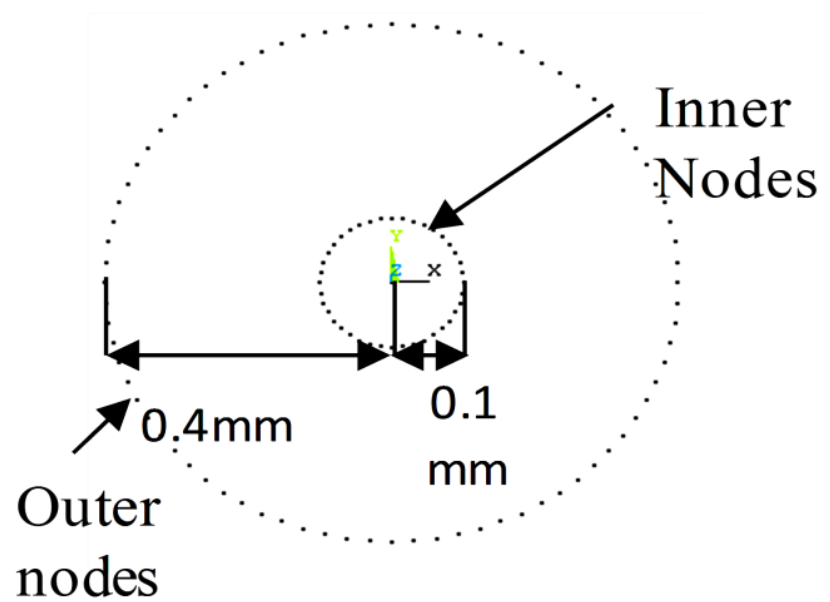

Fig. 6. Quarter point elements at the crack tip.

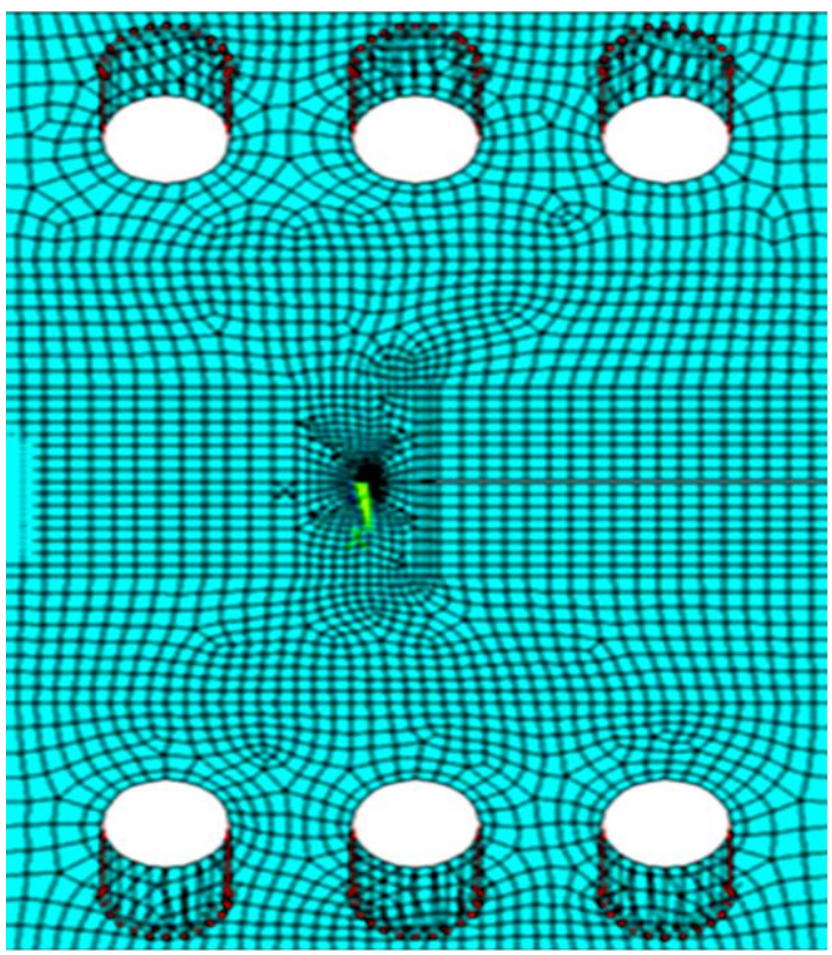

Fig. 7. Meshed model with boundary conditions.

In linear elastic problems, it has been shown that the displacements near the crack tip (or crack front) vary as $\sqrt{ }$, where ' $r$ ' is the distance from the crack tip. The stresses and strains are singular at the crack tip, varying as $1 / \sqrt{ }$ r. To pick up the singularity in the strain, the crack faces should be coincident, and the elements around the crack tip (or crack front) should be quadratic, with the middle side nodes placed at the quarter points. Such elements are called singular. The recommended element type for 3-D model is SOLID95 which is the 20-node brick element. This kind of element was used previously by P.S.Shivakumar Gouda [19]. Fig. 5 and Fig. 6 show the first row of elements at a distance of $0.1 \mathrm{~mm}$ from the crack tip around the crack front which should be singular elements. After modeling the 
crack model, as per the standard dimensions, a quarter point elements are created at the crack tip.

\section{Boundary conditions}

The model is constrained in all degrees of freedom at the opposite side of crack to avoid the rigid body motion of the model. The tensile load is applied on the top half portion of the hole to simulate the pin load condition as shown in Fig. 7. The different modes of fracture are obtained by rotating the nodes of interest by required angle.

\section{Results and discussion}

Experiments have been carried out to characterize the candidate composite material under different loading conditions and with various specimen configurations. The analysis of the results and the influence of various parameters on the properties are summarized in the following sections.

\section{Tensile behavior of hybrid polymer composite}

Six specimens from each fiber orientation of the composite were tested. The dimensions of the test coupons were 165 $\mathrm{mm}$ in length, $12 \mathrm{~mm}$ in width and $4 \mathrm{~mm}$ in thickness respectively. The 12 sample specimens were tested at a cross-head speed of $5 \mathrm{~mm} / \mathrm{min}$. The elastic constants of high silica glass satin - epoxy composite used in this investigation are summarized in Table $\mathbf{1}$.

Table 1. The average values of elastic properties of high silica glass-satin textile epoxy hybrid polymer composite.

\begin{tabular}{lccccccccc}
\hline Material & $\mathrm{E}_{1}(\mathrm{MPa})$ & $\mathrm{E}_{2}(\mathrm{MPa})$ & $\mathrm{E}_{3}(\mathrm{MPa})$ & $\mathrm{G}_{1}(\mathrm{MPa})$ & $\mathrm{G}_{2}(\mathrm{MPa})$ & $\mathrm{G}_{3}(\mathrm{MPa})$ & $\mu_{1}$ & $\mu_{2}$ & $\mu_{3}$ \\
\hline $\begin{array}{l}\text { S-Glass- } \\
\text { Satin }\end{array}$ & & & & & & & & & \\
Epoxy & 7414.8 & 6831.33 & 3561.53 & 2851.85 & 2627.44 & 1369.62 & 0.3 & 0.3 & 0.3 \\
Composite & & & & & & & & & \\
\hline
\end{tabular}

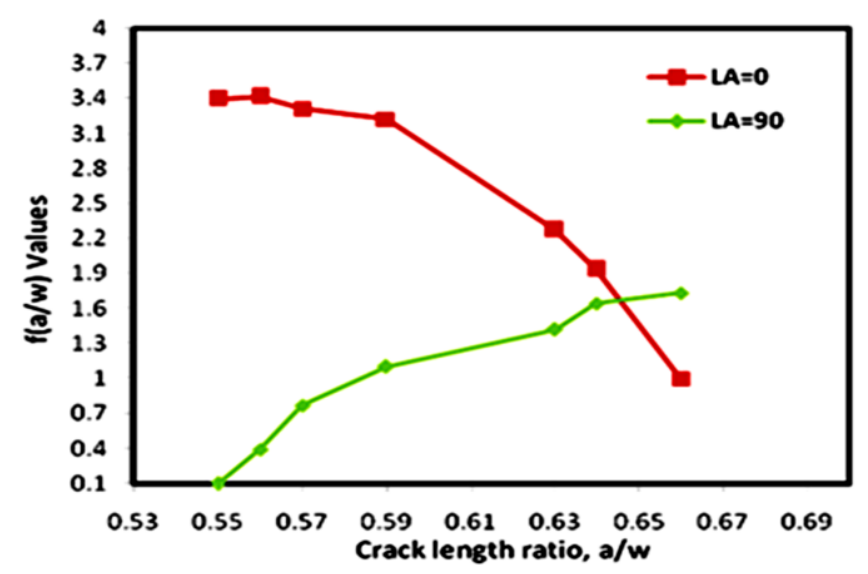

Fig. 8. Non dimensitional stress intensity factors v/s crack length ratio.

\section{Fracture behavior of hybrid polymer composite}

The critical stress intensity factors $\left(\mathrm{K}_{\mathrm{Ic}}\right.$ and $\left.\mathrm{K}_{\mathrm{IIc}}\right)$ are estimated by using geometrical factors or non-dimensional stress intensity factors $f_{1}(a / w)$ and $f_{2}(a / w)$ as given in LiChun Bian and Kwang Soo Kim [20]. The range of a/w ratio was found to be between 0.55 and 0.66 for different loading angles. Here $\mathrm{a} / \mathrm{w}$ is the crack length ratio, where ' $\mathrm{a}$ ' is the crack length and ' $w$ ' is the specimen width. Fig. 8 shows the changes in non dimensional stress intensity factors $f_{1}(a / w)$ for loading angle $(L A)=0^{0}$ and $f_{2}(a / w)$ for loading angle, (LA) $=90^{\circ}$ due to change in crack length. The changes of the computed values on mode-I and modeII non dimensional stress intensity factors are largely due to the variation in crack length ratio. Therefore the increase of the crack length leads to a reduction of mode-I fracture resistance, similarly the increase of the crack length leads to increase of mode-II fracture resistance.

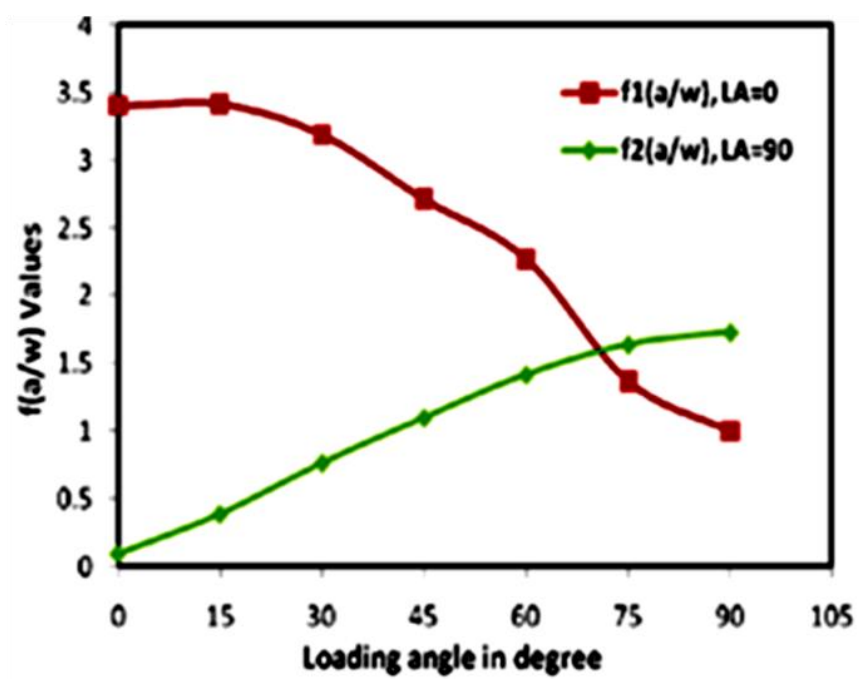

Fig. 9. Non dimensional stress intensity factors v/s loading angle.

Further, the computed values of non dimensional stress intensity factors are plotted against the diferent loading angles as shown in Fig. 9. The figure infers that as mode-II loading contribution increases, the mode-I stress intensity factor decreases and mode-II stress intensity factor increases. It is also observed that for loading angles $\alpha \leq 60^{\circ}$, the mode-I fracture becomes dominant. For $\alpha \geq 75^{\circ}$ mode-II fracture becomes dominant. The natures of variation of these results are in good agreement with similar earlier results [21].

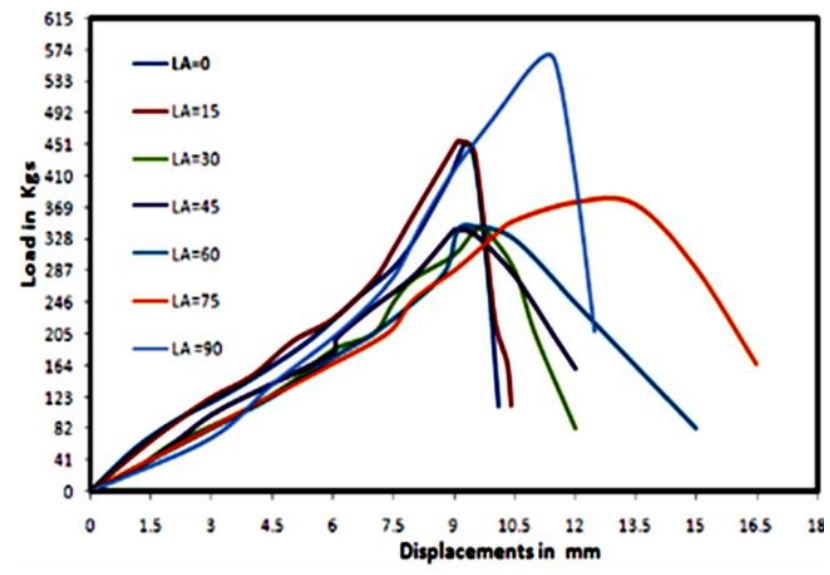

Fig. 10. Load v/s displacements curves for CTS specimen with varying loading angle.

The load displacement curves from the experimental fracture tests are shown in Fig.10. From the curves, the 
peak load $\left(\mathrm{P}_{\mathrm{C}}\right)$ at fracture are used to compute critical mode-I and mode-II stress intensity factors using [22-24].

$$
\begin{aligned}
& K_{I}=\frac{P_{C} \sqrt{\pi a}}{w t} f_{I}(a / w) \\
& K_{I I}=\frac{P_{C} \sqrt{\pi a}}{w t} f_{I I}(a / w)
\end{aligned}
$$

Here ' $\mathrm{P}_{\mathrm{c}}$ ' is the average critical load, ' $\mathrm{t}$ ' is the thickness of the specimen and $f_{1}(a / w)$ and $f_{2}(a / w)$ are the non dimensional geometrical factors for both pure mode-I and pure mode-II. Fracture tests were performed with a universal tensile testing machine under a loading speed of 5 $\mathrm{mm}$ per minute. Tests were conducted three times for each loading angle.

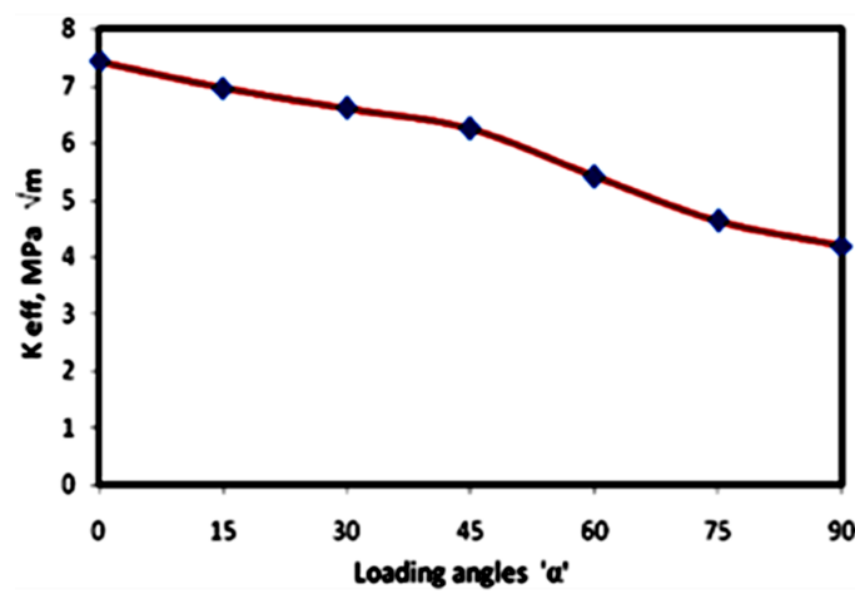

Fig. 11. Variation of $\mathrm{K}_{\mathrm{eff}} \mathrm{v} / \mathrm{s}$ loading angle ' $\alpha$ '.

Load displacement curves were used to generate average fracture load for each loading angle as shown in the Table 2. The variation in load values $\left(\mathrm{P}_{\mathrm{C}}\right)$ observed in the Table 2 is because of errors in manual method of composite fabrication and curing at room temperature. The fracture toughness was determined experimentally with compact tension shear specimen under different mixed mode loading conditions. Average values of mixed mode critical stress intensity factors for glass-satin HPC are summarized in Table 3.

Table. 2. Average critical mixed - mode fracture loads Pc for high silica

\begin{tabular}{|c|c|c|c|c|c|c|c|c|}
\hline $\begin{array}{l}\text { Loading } \\
\text { Angle }\end{array}$ & $\begin{array}{l}\text { Specimen } \\
\text { Number }\end{array}$ & $0^{0}$ & $15^{0}$ & $30^{\circ}$ & $45^{0}$ & $60^{\circ}$ & $75^{0}$ & $90^{\circ}$ \\
\hline \multirow{4}{*}{$\begin{array}{c}\mathbf{P}_{\mathrm{c}} \\
\text { (Newton) }\end{array}$} & 1 & 3650 & 2650 & 2750 & 3580 & 3392 & 3720 & 5690 \\
\hline & 2 & 4520 & 4570 & 3381 & 3960 & 3427 & 3528 & 3390 \\
\hline & 3 & 3750 & 3712 & 3010 & 3780 & 3510 & 3568 & 4560 \\
\hline & Average & 3973 & 3644 & 3047 & 3773 & 3443 & 3605 & 4546 \\
\hline
\end{tabular}
glass-satin textile hybrid polymer composite.

The effective stress intensity factors $\left(\mathrm{K}_{\text {eff }}\right)$ in mixed mode loading have been calculated using the relationship, $\mathrm{K}_{\mathrm{eff}}=\left(\mathrm{K}_{\mathrm{I}}^{2}+\mathrm{K}_{\mathrm{II}}^{2}\right)^{1 / 2}$ as given in [25]. The estimated $\mathrm{K}_{\mathrm{eff}}$ values are plotted against loading and shown in Fig. 11. The figure shows that for a particular load the magnitude of $\mathrm{K}_{\text {eff }}$ decreases as ' $\alpha$ ' increases. It is also clear from the Fig.
11, that for a particular applied load $\mathrm{K}_{\mathrm{eff}}$ in mode-I $\left(\mathrm{LA}=0^{0}\right)$ is more than that of mode-II $\left(\mathrm{LA}=90^{\circ}\right)$.

Table. 3. Average critical stress intensity factors $\left(\mathrm{K}_{\mathrm{Ic}}\right)\left[\mathrm{Mpa} \mathrm{m}{ }^{1 / 2}\right]$ for high

\begin{tabular}{|c|c|c|c|c|c|c|c|c|}
\hline \multirow{2}{*}{$\begin{array}{l}\text { Stress } \\
\text { intensity } \\
\text { factors }\end{array}$} & & \multicolumn{7}{|c|}{ Loading angles } \\
\hline & & $0^{0}$ & $15^{0}$ & $30^{\circ}$ & $45^{\circ}$ & $60^{\circ}$ & $75^{\circ}$ & $90^{\circ}$ \\
\hline $\mathrm{K}_{\mathrm{c}}$ & $\mathrm{K}_{\mathrm{IC}}$ & 7.431 & 6.917 & 5.453 & 5.799 & 4.595 & 2.967 & -- \\
\hline$\left(\mathrm{Mpa} \mathrm{m}{ }^{1 / 2}\right)$ & $\mathrm{K}_{\| \mathrm{C}}$ & -- & 0.797 & 1.316 & 2.355 & 2.872 & 3.567 & 4.199 \\
\hline
\end{tabular}
silica glass - satin textile hybrid polymer composite.

It is observed from the Table $\mathbf{3}$, that $\mathrm{K}_{\mathrm{IC}}$ increases until $\alpha=60^{\circ}$ and then decreases and $\mathrm{K}_{\text {IIC }}$ increases as the modeII loading contribution i.e as ' $\alpha$ ' increases from $0^{\circ}$ to $90^{\circ}$. For loading angles $\alpha \leq 60^{\circ}$, the mode-I contribution is greater than that of mode-II and the opening mode fracture becomes dominant. For loading angles $\alpha \geq 75^{\circ}$, there is an opposite trend. The shearing mode fracture becomes dominant, it can be seen from Table 3, that the opening mode $\left(\alpha=0^{0}\right)$ stress intensity factor is larger than the shearing mode $\left(\alpha=90^{\circ}\right)$ stress intensity factor. This means that, the cracked specimens are tougher in tensile loading conditions and weaker in shearing loading conditions. The researchers [8-11] have been proposed a number of mixed mode fracture criteria for describing the interlaminar fracture of composites. These criteria are relevant to those used for isotropic materials. Fracture criteria can be formulated based on the deferent fracture parameters like stress intensity factor (SIF) or energy release rate for which the critical fracture parameters $\left(\mathrm{K}_{\mathrm{C}}\right.$ or $\left.\mathrm{G}_{\mathrm{C}}\right)$ can be determined experimentally. In recent research studies, the energy release rate during fracture were used preferably as fracture parameters but for composites, the stress intensity factors, which are also equally important to characterize the fracture in polymer composites in the present paper, showed to be more useful and common.
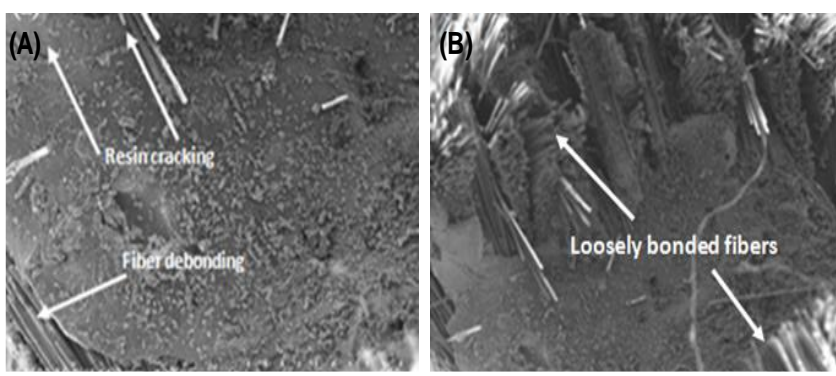

Fig. 12. SEM graph showing fracture surfaces of pure model-I loading $\left(\alpha=0^{\circ}\right)$. (A) Resin cracking with fiber deboning and (B) clear deboning between fibers.

\section{Fractography analysis}

Investigations of fracture surfaces by scanning electron microscopy are necessary to determine the failure criteria and further to identify the mechanism involved in toughening by observing the phase morphology in cross linked epoxy matrix structure. Furthermore, the resin fracture analysis should indicate the concentration and dispersion of the toughness and also it should help to optimize the level of toughness modification and hopefully relate to results obtained from the composite fracture 
toughness test conducted for various loading angles. All fracture surfaces were subsequently examined in scanning electron microscope to determine the degree of resin fracture and degree of micro cracking which precedes the fracture were determined by hackles [26] on the fractured surfaces. Fracture surfaces of pure mode-I $\left(\alpha=0^{0}\right)$, are shown in Fig. 12. The brittle fracture from pure mode-I failure was characterized by a smooth corrugated surface with resin cracking which could also be the result of fiber debonding in the interface of two fibers. However the weak interface does not necessarily refer to the low fracture toughness.

Interfacial failures somehow cause fiber bridging that enhances the delamination growth and combined with fiber pull-out will dissipate additional energy. SEM micrographs also revealed that the fracture surfaces of the high silica glass-satin epoxy composite changes with mixed mode ratio. Figures $13 \mathrm{a}$ and $\mathrm{b}$ show the fracture surfaces at mixed mode I/II loading conditions $\left(\alpha=45^{\circ}\right)$.
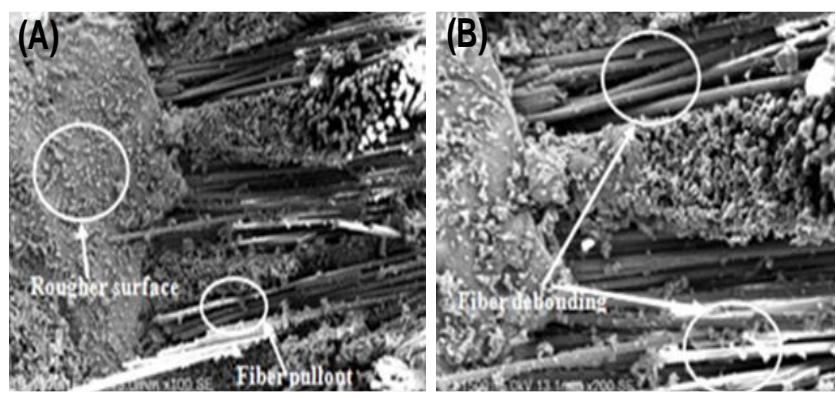

Fig. 13 (A) \& (B). SEM graph showing fracture surfaces of mixed mode loading of $\alpha=450$.
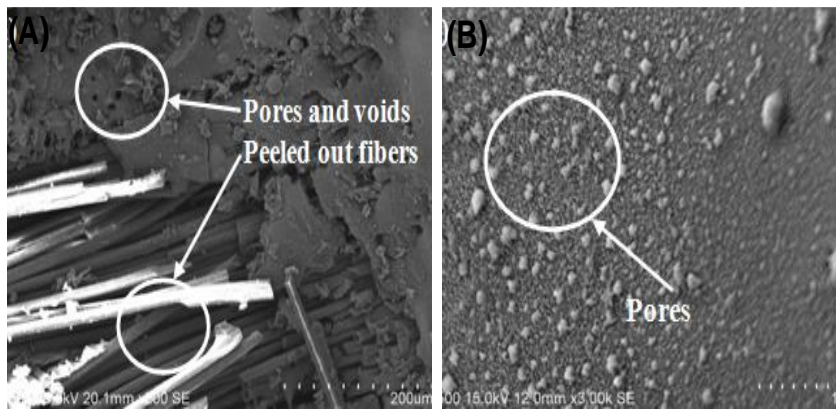

Fig. 14 (A) \& (B). SEM graph showing fracture surfaces of mixed mode loading of $\alpha=30^{\circ}$.

From the earlier discussion about pure mode-I, the fracture surface was very flat indicating a brittle cracking of resin which would explain the high mode-I fracture toughness. As mode-II loading contribution is added, the fracture surfaces become rougher (Fig. 13 (A)) and fiber debonding (Fig. 13(B)) as observed in the SEM image taken on the fracture surface for Mode-(I + II) loading angle increases. Troughs and hackles have appeared where fibers were pulled away from the matrix (Fig. 13 (A)) indicating interracial failure. Hackles are the parts of the matrix deformation between adjacent fibers that are lifted up parallel to one another and tend to slant in the same direction over the entire surface.

The observation of the mixed mode loading $\left(\alpha=30^{\circ}\right)$, the fracture surface carried out with scanning electron microscopy (SEM) revealed that the fracture surfaces of the high silica glass-satin epoxy composite change with mixed mode loading as shown in figure14 a and b. Fracture surface showed evidence of some distributed pores and voids (Fig. 14a and b). Some fibers were peeled out which show the presence of mode-I loading component. The fracture surface shows the traces of fibers in the resin regions combined with voids and debonded fibers.
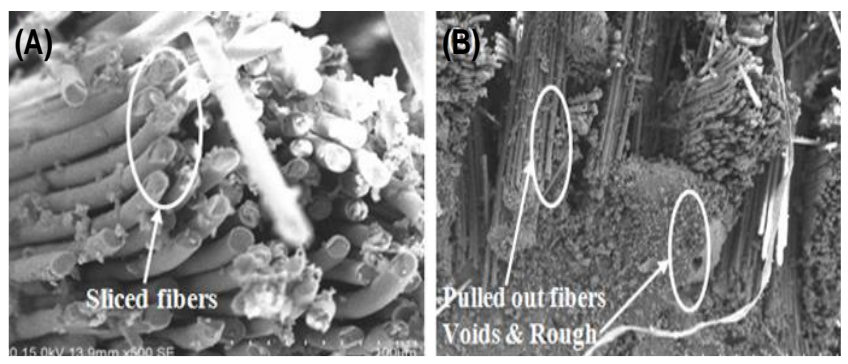

Fig. 15 (A) \& (B). SEM graph showing fracture surfaces of pure mode-II loading of $\alpha=90^{\circ}$.

Fig. 15 (A) shows the factrograph of pure mode-II fracture surface. It is seen that the fibers are sliced at numerous inclined angles. From Fig. 15 (B), it is clear that the fibers have been pulled out from the matrix indicating interfacial failure. However, due to large relative motion in mode-II loading, the fracture surface was rough and more voids, debonded particles were detected. The presence of voids with soiled appearance indicates that ductile crack propagation conditions are favoured with respect to the mode-I case because an increased shear deformation exists in mode-II loading. As the mode-II loading contribution increases, the fracture surface becomes rougher and slicing of fiber at an angle can be observed.

Table 4. Experimental and FE results of $\mathrm{K}_{\mathrm{IC}} \& \mathrm{~K}_{\mathrm{IIC}}$ for CTS specimen with different loading angles.

\begin{tabular}{|c|c|c|c|c|c|c|c|c|}
\hline $\begin{array}{l}\text { Average } \\
\text { Load(N) }\end{array}$ & $\begin{array}{l}\text { Loading } \\
\text { Angle(a) }\end{array}$ & $\begin{array}{l}\text { Crack } \\
\text { Length }\end{array}$ & $\begin{array}{l}\mathrm{K}_{\mathrm{IC}}(\text { Exp) } \\
\mathrm{MPa} / \mathrm{m}\end{array}$ & $\begin{array}{l}\mathrm{K}_{\mathrm{IC}} \text { (Ansys) } \\
\mathrm{MPa} / \mathrm{m}\end{array}$ & $\begin{array}{l}\text { Error } \\
(\%)\end{array}$ & $\begin{array}{l}\mathrm{K}_{\mathrm{IIC}}(\operatorname{Exp}) \\
\mathrm{MPa} / \mathrm{Vm}\end{array}$ & $\begin{array}{l}\mathrm{K}_{\text {ICC }} \text { (Ansys) } \\
\mathrm{MPa} / \mathrm{m}\end{array}$ & $\begin{array}{l}\text { Error } \\
(\%)\end{array}$ \\
\hline 3973 & $0^{0}$ & 5 & 7.431 & 6.316 & 15.00 & - & - & - \\
\hline 3644 & $15^{\circ}$ & 6 & 6.917 & 5.775 & 16.51 & 0.797 & 0.669 & 16.06 \\
\hline 3047 & $30^{\circ}$ & 7 & 5.453 & 4.744 & 13.00 & 1.316 & 1.118 & 15.04 \\
\hline 3773 & $45^{\circ}$ & 8 & 5.799 & 4.987 & 14.00 & 2.355 & 2.013 & 14.52 \\
\hline 3443 & $60^{\circ}$ & 12 & 4.595 & 3.882 & 15.50 & 2.872 & 2.426 & 15.52 \\
\hline 3605 & $75^{\circ}$ & 15 & 2.967 & 2.581 & 13.00 & 3.567 & 2.996 & 16.00 \\
\hline 4546 & $90^{\circ}$ & 10 & - & - & - & 4.199 & 3.653 & 13.00 \\
\hline
\end{tabular}

\section{$F$ E Analysis of mixed mode (I+II) fracture behavior of hybrid polymer composite}

The general-purpose finite element (FE) code ANSYS was used in this study. CTS specimen is subjected to pure mode-I to pure mode-II and wide range of mixed mode loadings has been considered in the present study. The required orthotropic material properties, maximum load and crack length are inputed which are obtained previously through experimental tensile and fracture test. The loading and displacement boundary conditions were used in this analysis. Three-dimensional elastic FE calculations were performed using SOLID95, the 20-node higher order brick elements. In these calculations, the material behavior has 
been considered to be linear elastic. The stress intensity factors in mode-I and mode-II loading have been computed for various loadings and crack lengths using ANSYS post processor. The magnitudes of experimental $\mathrm{K}_{\text {IC }}$ and $\mathrm{K}_{\text {IIC }}$ are compared with FE results and cited in the Table 4.

The results indicate that there exists some discrepancy in estimation of stress intensity factors by experimental fracture test and present $\mathrm{FE}$ results. It is found that there is $15 \%$ to $16 \%$ error in estimation of $\mathrm{K}_{\mathrm{IC}}$ and $\mathrm{K}_{\mathrm{IIC}}$. This discrepancy in estimated magnitudes of stress intensity factors attributed to varied loading conditions in experimental fracture test through loading fixtures. It is observed from Table 4, that the stress intensity factor for mode $I$ is greater up to an angle $\alpha=60^{\circ}$ and for loading angles $\alpha \leq 60^{\circ}$, the mode-I contribution is greater than that of mode-II and the opening mode fracture becomes dominant. This is in similar agreement with experimental results.

\section{Conclusion}

The major conclusions derived from this investigation are as follows:

i. The numerical results indicated that for loading angles close to pure mode-II, a high ratio of mode-II to modeI fracture is dominant and there is an opposite trend for loading angles close to pure mode-I.

ii. Finite element results witnessed that the increase of the mode-II loading contribution leads to an increase of fracture resistance in the woven high silica glass and satin textile epoxy composite and increase of crack length leads to reduction of resistance to fracture.

iii. The results indicate that there exists some discrepancy in estimation of stress intensity factor by experimental fracture test and present FE results. This discrepancy in estimated magnitudes of stress intensity factor attributed to varied loading conditions in experimental fracture test through loading fixtures.

iv. The observation of fracture surface showed that the mode-I fracture surface is of a brittle matrix cracking with relatively smooth flat matrix fracture and shows a little debonding between fiber and matrix.

v. As the mode -II loading contribution increases, the fracture surfaces become rougher and sliced fibers at an angle can be observed.

\footnotetext{
Acknowledgements

The authors thank GLS Polymers Private Limited, Bangalore for providing testing facility to take up this work. The authors express their gratitude to Dr. S.Mohankumar, Principal, and the Management, S.D.M College of Engineering and Technology, Dharwad, Karnataka, India, Prof. M.R.Wisnom, Professor in Aerospace structures, ACCIS, University of Bristol, UK, and Dr.S.T. Nandibewoor, Chairman, Department of PG Studies in Chemistry, Karnatak University, Dharwad and also the staff of Mechanical Engineering Department, S.D.M College of Engineering and Technology, and the facility provided for SEM examinations at R.V. College of Engineering, Bangalore, India.
}

\section{Reference}

1. M.M Thwe., K Liao. Comp. Sci. Tech, 2003, 63, 375, DOI: $\underline{\text { S0266-3538(02)0225-7 }}$

2. M.S Sreekala., J.George, M.G Kumaran., S. Thomas, Comp. Sci. Technol. 2002, 62, 339.

DOI: $10.1177 / 0731684405041717$
3. James R. Reeder. K. Song, P. Chunchu, D. R. Ambur, "Post buckling and growth of delamination in composite plates subjected to axial compression." AIAA journal, 2002.

DOI: $10.2514 / 3.9894$

4. James R. Reeder and John R. Crews. "Mixed Mode Bending Method for Delamination Testing." Published in AIAA Journal, 1990, 28, 1270-1276,

DOI: $10.2514 / 3.25204$

5. L. P. Borrego , F. V. Antunes, Fatigue Crack Growth Behaviour Under Mixed-Mode Loading, anales de mecánica de la fractura, 2005 vol. 22.

6. M.G.D. Geers R. De Borst, T. Peijs, Mixed mode numericalexperimental investigations of non-local characteristics of randomfiber-reinforced composites, Composites Science and Technology, 1999, 59, 569. DOI: $10.1016 / \mathrm{S} 0266-3538(99) 00017-2$

7. P. Naghipour, M. Bartsch, Effect of fiber angle orientation and stacking sequence on mixedmode fracture toughness of carbon fiber reinforced plastics: Numerical and experimental investigations, Journal of Materials Science and Engineering (2009). DOI: $10.1016 /$ J.MSEA.2009.07.069.

8. M. Nikbakht, and N. Choupani, Numerical Investigation of Delamination in Carbon-Epoxy Composite using Arcan Specimen, International Journal of Mechanical, Industrial and Aerospace Engineering, 2(4), 2008, 259

DOI: $10.4028 /$ www.scientific.net/KEM.471-472.880

9. Robert Zemcik \& Vladislav Las, Numerical and Experimental Analyses of the Delamination of Cross-Ply Laminates, Journal of Materials and technology, 42 (4), 2008, 171. DOI: $678.6 / .7: 620.18$

10. Hossein Saidpour, Mehdi Barikani, and Mutlu Sezen, Mode-II Interlaminar Fracture Toughness of Carbon/Epoxy Laminates, Iranian Polymer Journal, 12 (5),2003, 389. DOI: $\underline{10552 / 1033}$

11. Richard HA, Benitz K. A loading device for the creation of mixed mode in fracture mechanics. Int J Fracture, 22,1983, R55. DOI: S0013-7944(98)00068-X

12. Nisitani H, Ishihara T, editors. Proceedings of Intl. Conference on the Role of Fracture Mechanics in Modern Technology. Fukuoka, Japan, North-Holland: Amsterdam, 1986, 577.

13. Valluri SR, Taplin DMR, Ram Rao P, Knott JF, Dubey R, editors. Advances in fracture research, Proc $6^{\text {th }}$ Int Conf on Fracture (ICF6), New Delhi, India, Oxford: Pergamon Press, 5, 1984, 3337-3344.

14. Autar K.Kaw, "Mechanics of Composite Materials", 2nd Edition, Taylor \& Francis Group Publications, New York, 1999. DOI: $10.1201 / 9781420058291$.fmatt.

15. M.M.Schwartz, Composite Materials Handbook, McGraw - Hill book Company,New York. DOI: $10.1007 / \mathrm{BF} 02669621$

16. ASTM Standards, "ASTM D3039: Standard Test Method for Tensile Properties of Polymer Matrix Composite Materials," ASTM, West Conshohohoken, PA, 1983, 99. DOI: $10.1361 /$ CFAP2003P417

17. Standard Test Method for Mixed Mode I - Mode II Interlaminar Fracture Toughness of Unidirectional Fiber Reinforced Polymer Matrix Composites, ASTM D6671/ASTM D 6671M-06, West Conshohohoken, PA, 2011,1

DOI: $10.1177 / 1099636209104533$

18. Ansys 11, User manual, SAS IP, Inc ,2005.

19. P.S. Shivakumar Gouda, S.K. Kudari, Prabhuswamy. S, Dayananda Jawali, "Fracture Toughness of Glass-Carbon (0/90)S Fiber Reinforced Polymer Composite - An Experimental and Numerical Study" Journal of Minerals \& Materials Characterization \& Engineering, , ,Printed in the USA, 10(8), 2011, 671 .

ISSN: $1539-2511$

20. Li-Chun Bian, Kwang Soo Kim "The minimum plasti zone radius criterion for crack initiation direction applied to surface cracks and through-cracks under mixed mode loading, Intl.J of Fatigue, Elsevier Publications, 2004 26, 1169. DOI: U0005-0102200810013100

21. M. Nikbakht, and N. Choupani, Experimental investigation of mixed mode fracture behaviour of woven laminated composites, Intl.J of material Science, 2009, 44, 3428 . DOI: $10.1016 /$ J.MSEA.2007.05.103.

22. Jurf RA, Pipes RB. "Interlaminar fracture of composite materials" J Comp Mater, 1982 (16) 386.

DOI: $10.1016 / 0010-4361(89) 90211-5$. 
23. Yoon $\mathrm{SH}$, Hong $\mathrm{CS}$ "Interlaminar fracture toughness of graphite/epoxy under mixed mode deformations" Experimental Mechanics, 1990 (30), 234.

DOI: $10.1007 / \mathrm{BF} 02322816$.

24. Choupani, N., "Experimental and Numerical Investigation of the Mixed-mode Delamination in Arcan Laminated Specimens" Journal of Materials Science \& Engineering A, (478) 229, 2008

DOI: $10.1016 /$ J.MSEA.2007.05.103.

25. K.H. Benrahou and M.Benguediab, M.Belhouri, Nait-Abdelaziz \& A.Imad, "Estimation of plastic zone by finite element method under mixed mode (I\&II) loading", Computational Material Sciences, 2007, 38,595 .

DOI: $10.1016 / J . C O M M A T S C I .2006 .04 .001$.

26. Morris G.E., Determining fracture directions and fracture origins on failed graphite/epoxy surfaces. Non-destructive evaluation and flaw critically for composite materials, ASTM STP 696, Pipes R.B (Ed), 1979, 274.

ISBN: 0-8031-0950-4.

\section{Advanced Materials Letters}

\section{Publish your article in this journal}

ADVANCED MATERIALS Letters is an international journal published quarterly. The journal is intended to provide top-quality peer-reviewed research papers in the fascinating field of materials science particularly in the area of structure, synthesis and processing, characterization, advanced-state properties, and applications of materials. All articles are indexed on various databases including $\underline{\mathrm{DOAJ}}$ and are available for download for free. The manuscript management system is completely electronic and has fast and fair peer-review process. The journal includes review articles, research articles, notes, letter to editor and short communications. 